\title{
Chapter 22 \\ Proposal for a Pact for National \\ Responsibility Through EU Solidarity \\ Within the Present EU Architecture
}

\section{Christian Ghymers}

\begin{abstract}
This Chapter shows that there still exist urgent actions possible with existing tools and procedures for breaking the prisoner dilemma through modalities of solidarity leading to more responsibility. These feasible solutions are simple recipes based upon past experiences for opening again the European Union (EU) winwin game by activating conditional incentives able to enhance channelled financial market reactions favourable to adjusting countries, preventing self-fulfilling speculation and benefiting the whole EU.
\end{abstract}

\section{Introduction}

Northern European Union (EU) member states (MS) fear that solidarity financing could weaken national responsibility and postpone the necessary budgetary consolidation in the South. However, this position has made more difficult any adjustment and increased the gravity of the crisis, with Southern economies falling in deeper depression, worsening their fiscal position but also leading to depressing spillovers to the North. This "loss-loss" game illustrates the "prisoner dilemma" impeding solidarity and responsibility in the euro-area: the European Central Bank (ECB) cannot give liquidity without guarantee of effective fiscal sustainability while fiscal sustainability is impossible without a liquidity safety net for preventing contagion and rescuing treasuries in liquidity trouble even when they try to adjust. A significant part of this deadlock comes from the overwhelming dogmatic ideas relative to spontaneous efficiency of free markets-especially for financial markets-combined with the rent-seeking interests of incumbent authorities whatever left or right.

In a nutshell, this general dogmatic belief has led to combine two big "technical" mistakes of the Economic and Monetary Union (EMU) architecture:

\footnotetext{
C. Ghymers $(\square)$

Founder and Co-coordinator of the Jean Monnet Network "Crisis-Equity-Democracy

for Europe and Latin America”, IRELAC, Brussels, Belgium
} 
(i) The euro-area remains especially exposed to the destabilizing power of wild financial markets because it is the only monetary area in the world without a genuine Lender-of-Last-Resort (LOLR) and without credible mechanisms of solidarity among its members. In the EMU, this gives financial markets the power to precipitate a liquidity crisis (and even to turn it into a solvency crisis cfr. Spain) in a one-bet speculation in case of doubts on sovereign debts because national treasuries cannot control, by definition, the currency and the exchange rate in which they issue their debt, like Argentina during its currency board with the dollar.

(ii) This fatal caveat was combined with a surveillance process of national policies, which remained excessively intergovernmental and imbalanced, with ministers playing as "Judges and Parts". It focused almost exclusively upon fiscal policies (Stability and Growth Pact-SGP) and adopted a benign neglect about the divergences and current account disequilibrium that the single currency inevitably had to imply. ${ }^{1}$ The argument of financial efficiency was used for presenting these results as sound because they are the inner advantage of the single currency, which eradicates saving constraints, allowing both left and right governments to satisfy their respective electorates in such an EMU regime spurring consumption, indebtedness and speculation, but accumulating unsustainable disequilibrium within the euro-area.

The same dogmatism explains the refuse to care about the credit-boom and the unproductive uses of these huge free capital flows in the Southern economies, even in the surveillance exercises of the Commission/ECOFIN! Such degree of incompetence had inevitably to be sanctioned by citizen reactions once the artificial benefits of the single currency vanished, increasing unfair inequalities, insecurity feelings among EU citizens and distrust among MS, trapping them into a typical "prisoner dilemma". Unfortunately, but logically, the euro and the EU became the easiest scapegoat for the failure to bring a visible value added.

Although these mistakes must be corrected anyway through a new EU architecture with a new EMU Treaty, the necessary consensus needs too much time before being ready for facing the new coming difficulties and crisis. Therefore, this Chapter shows that there still exist urgent actions possible with existing tools and procedures for breaking the prisoner dilemma through modalities of solidarity leading to more responsibility. These feasible solutions are simple recipes based upon past experiences for opening again the EU win-win game by activating conditional incentives able to enhance channelled financial market reactions favourable to

\footnotetext{
${ }^{1}$ With a single nominal interest rate and inflation rates higher in the South than in the North (price level convergence and growth differentials), inevitably real interest rates are too low in the South and too high in the North, creating credit-boom in the South amplified by huge capital movements from the North to the South but in speculative investment spurring consumption. This is basic economics and would have required special policy measures with other tools yet available (bank reserve requirements, capital ratio, prudential regulations) at national level, but dogmatism was used by politicians and even in the Commission the answer given to the current account imbalances in the South financed by capital inflows was that "markets know better that civil servants".
} 
adjusting countries, preventing self-fulfilling speculation and benefiting the whole EU.

\section{The Basic Principles for Breaking Out the EMU Prisoner Dilemma Blocking EMU Governance}

Solving the present prisoner dilemma relies upon correcting the two caveats of the present EMU by linking visibly national responsibility to the access to cheap conditional EU solidarity funds. As demonstrated in the last decade by the disasters of the over indebtedness cases (Greek, Spain, Portugal and Ireland), the way the budgetary consolidations were imposed became very counterproductive and damaging for all EU partners. Making available adequate conditional EU solidarity could give immediate positive results through their powerful impacts on the spreads of sovereign bonds and the positive growth spillovers for both debtors and creditors.

Analyses of the facts and the history of the EU integration tends to show that integration progress depends upon the degree of mutual confidence among member states, which is fragile but reversible as shown by past episodes of European integration. Observation of four decades of monitoring economic policy coordination and of EMU process permits to draw three intertwined lessons:

(i) Confidence among Member States as well as citizens with respect to EU requires a clear deal between solidarity and responsibility;

(ii) This deal needs a credible process of collegial monitoring based upon factual indicators allowing for national policymakers to work together for building trust and consensus on common interests and making citizens more aware of the convergence between national self-interests and the shared euro interests, that is, to make explicit and tangible the win-win game at stake and the cost/ benefit challenge of national responsibility giving right to solidarity.

(iii) All the attempts since the very beginning of the EU to coordinate national policies failed as far as they were conceived as a central coordination, while they succeeded when they resulted from the progressive awareness of the selfinterest at stake for each Member State to respect by their own sovereign decisions the common discipline and interests (Ghymers 2015).

These lessons explain that coordination among sovereign states never works for the sake of "general interest" but only for the selfish interests of governments and their electorates. Therefore, it is possible to use this basic principle for activating specific tools revealing the self-interests of each sovereign government to converge. This explains the success of the European Monetary System (EMS) with its exchange-rate mechanism (ERM) which "internalized" visibly the consequences of policy choices and the degree of solidarity (Ghymers 1995) and allowed for forging (progressively) a consensus thanks to a clever procedure combining: 
(i) The collegial monitoring of the ERM imposed automatically by the European Currency Unit (ECU) which effectively "multilaterialized" all bilateral parities, because any exchange-rate adjustments had to be bargained collegially ${ }^{2}$ through a peer review of sovereign policies at EU level, and;

(ii) Monitoring the impacts of these sovereign policies upon the exchange rates and the spreads of interest rates.

The following proposals are based upon these ERM lessons transposed to the single currency for internalizing national policies by influencing financial markets through two linked key tools correcting the two major failures of EMU:

(i) A less discretionary and more powerful system of solidarity (in the ERM, the solidarity was used very selectively by the monetary hegemon, Germany and the Bundesbank);

(ii) A more objective and less intergovernmental monitoring of all national policies.

These two instruments could be made quickly available inside the present imperfect treaty by using current procedures and instruments.

\section{The Proposed Recipes for Redeeming the Two Major Failures of the Euro-Governance}

The idea is to incentivize national responsibility by providing to adjusting MSs cheap but conditional EU financial assistance proposed by an independent monitoring, that is, exactly what the present EMU does not provide. Such a reconciliation between EU solidarity and MS responsibility results from two complementary initiatives:

1. To transform the European Stability Mechanism $\left(\mathrm{EMS}^{3}\right)$ - which is not a solidarity tool (no concessional loans but castigating loans with very high spread) and too limited size for compensating credibly the inhibition of the LOLR function of the ECB into an effective LOLR by changing it into an "European Debt Agency - EDA" offering conditional incentives for increasing national responsibility. EDA would use the Treaty as an EU public Bank (Art. 123, §2 see following section) for getting conditional access to ECB overdraft facilities for short-term liquidity assistance and, by ECOFIN decision, could also issue-

\footnotetext{
${ }^{2}$ Because the ECU basket was a fixed number of national currencies, any change in the parity of one member implies arithmetically that all the other central parities also do change, therefore requiring a collegial agreement, thus opening a discussion on the policy adjustments for making sustainable the new parities as a formal condition imposed by the partners for accepting the demand for realignment from one of the MS.

${ }^{3}$ Created in 2012 with a special Treaty for replacing the temporary European Financial Stability Facility (EFSF) and the European Financial Stabilisation Mechanism (EFSM) created in 2010.
} 
under strict conditions-euro-bonds for supporting medium-to-long-run assistance to Member States under consensual structural adjustment.

2. To make attractive for MSs the respect of the conditions for access to the EDA loans by channelling financial markets reactions (spreads) with credible assessments and objective surveillance communiqués issued by a more independent monitoring body than the Commission/ECOFIN; this means to outsource to independent experts with the mandate to formulate public recommendations for preventing liquidity crisis without creating moral hazard situations. Commission/ ECOFIN decision procedures would still enact, amend or oppose to, but being fully accountable of any discrepancy with this new independent European Monitoring Board - EMB by "reversing the charge of the proofs", Commission/ ECOFIN having to demonstrate to public opinions their reasons for not following the independent surveillance exercise and its technical proposals.

The combination of these two simple ECOFIN decisions would reduce the inner myopia of financial markets by ensuring a credible guidance for preventing any selffulfilling speculation and turning them in a powerful support to sustainable and responsible national policies. The idea is to incentivize governments and get citizens' support for respecting strict conditions by organizing clear, simple, reduction in the interest-rate spreads when sovereign policies are credibly sustainable according to technical assessments issued by independent experts, validated by Commission/ECOFIN under the scrutiny of a broad, trans-European public debate. This means to stop the present bias of a too intergovernmental surveillance by the "judges \& parts" composing the ECOFIN.

\section{Concrete Modalities for Implementing the Two Proposed Recipes}

Art. $123 \S 2$ of the present Treaty provides the simple legal way for giving to the EMS a potential direct access to the ECB cash facilities, thus allowing this EMS to fulfil de-facto the role of an EU missing LOLR. Indeed, Article 123 in its $§ 1$ prohibits (correctly) any ECB loan or overdraft to any government or public institutions, but $\$ 2$ precisely sets (correctly too) that: "\$1 shall not apply to publicly owned credit institutions which, in the context of the supply of reserves by central banks, shall be given the same treatment by national central banks and the European Central Bank as private credit institutions". Thus, the Commission/ECOFIN decision process could - instantaneously - make the EMS a public bank of EU Member States—calling it "European Debt Agency - EDA"-for giving a clear signal to the financial markets that the euro-area has instantaneously the capacity to get unlimited liquidity in case of justified needs (under conditions) for giving emergency liquidity loans, stopping thus any one-bet speculation like what occurred in the worrying episode of the Euro sovereign-debt crisis, which would not have happened if the euro-area has had such an LOLR or a genuine Central Bank. 
Furthermore, in order to provide medium-to-long-run support to adjusting MSs, this EMS/EDA could issue its own euro-bonds under strict conditions imposed by ECOFIN. The purpose of this measure is triple: (i) to create an operational lever upon the spreads on sovereign bonds for supporting-always under conditionsconvergent policies by buying them (or swapping them) with euro-bonds, (ii) to develop the euro-bond market for accelerating the financial integration in the euroarea by improving liquidity conditions for euro-bonds, and (iii) to provide additional safe-assets which are the too-narrow base of the reversed pyramid of private liquidity which is pro-cyclical and exposed to run for safe assets once global activity turns negative. This would create a mechanism for "internalizing" the effects of respecting — or not — the common discipline: rewarding approved adjustment policies by reducing the interest-rate spreads imposed by myopic financial markets, that is, giving visible incentives to any member of the euro-area to respect the common rules, especially the fiscal discipline, while preventing wild overshooting resulting from the financial market excessive reactions.

More technically, the mechanism consists in three articulated successive steps:

(i) First, the introduction of a system of "blue-bonds versus red-bonds". Bonds getting the EU label of conformity of national fiscal policy with the common discipline become "Blue-bonds" and enjoy seniority and full guarantee from the EU MS, and all other sovereign bonds become "subordinated" (i.e. neither priority nor solidarity guarantee) and become "red-bonds" paying a higher spread in exchange for free sovereign issuance. Therefore, once an economy would not respect the fiscal discipline, all its bonds issued would be castigated automatically by a spread with respect to its past warranted blue-bonds. Such a spread permits to internalize very visibly the costs of the non-respect of the common rules or interests of the euro-area. The collegial assessment proposing the blue label and the conditionality relies upon an independent technical surveillance process (see following section).

(ii) Second, a solidarity arm with the possibility for EDA to conditionally buy or to swap red-bonds with its own EU bonds, improving liquidity conditions and reducing the spreads; even an adjusting economy like Greece could demand through the technical surveillance exercise (see below) to upgrade as bluebonds its new issuances when a formal stability programme is agreed upon with ECOFIN and duly implemented. This tool would give-immediate and costless - budgetary advantages to sustainable reforms/policies credibly committed with ECOFIN and monitored along a medium-term programme of reforms. It could also be possible to use the amount of swaps as a lever for influencing the spreads on sovereign red-bonds according to the speed of implementation of reforms or adjustments. EDA would make profits with the resulting appreciation of the red-bonds of adjusting economies, allowing to assess its efficiency and to build up free EDA reserves.

(iii) The next step would be to consider swapping all the sovereign blue-bonds by single EU-blue bonds issued by EDA. Indeed, all the euro-area members would be already solidary linked by their mutual guarantee given to the labelled sov- 
ereign blue-bonds. Therefore, additional liquidity advantages could result for all members (but especially to small/medium economies) and by the technical progress to get a genuine benchmark for the euro assets opening interesting perspectives of an additional coordination tool. The purpose of this proposed experimental new tool would be to unify progressively the euro-bond markets while respecting the no-bailing clause and increasing the enforcement power of the SGP through the self-interest of Member States to coordinate budgetary stances. This tool could be an attractive way to enforce the policy discipline without having to take financial sanctions in case of damaging policy divergences.

The whole philosophy behind a pact between more EU solidarity for more national responsibility relies entirely upon objective and credible technical conditionality. This has not been convincingly the case in the EMU governance. Therefore, for breaking the prisoner dilemma, the inseparable complementary initiative is to improve the transparency of the monitoring in charge of ECOFIN. Although a significant progress was made in 2015 with the creation of the European Fiscal Board (EFB) - an independent advisory committee of fiscal experts-the past period shows clearly several failures: intergovernmental bias with national Ministers behaving in the ECOFIN as "judge \& parts", lack of independence and courage of the Commission, lack of transparency and open public debates, and-most graveinsufficient coverage of the surveillance limited de facto to the SGP. No effective monitoring was possible before the crisis, and incumbent governments benefited electorally from the short-term advantages of the single currency. In the present situation, they try to benefit from their opposition to EU solidarity, demonstrating so that MSs behave as free riders with the EU, which indicates so an incoherence in the present Treaty and an abuse by the MSs in the EU decision-making.

This is why the recipe needs two components: (i) the scope of the "Independent European Monitoring Board - EMB" covers all the policies; (ii) the "charge of the proof" is reversed by giving the main role to the independent experts for assessing policies and proposing measures and conditionality, the Commission/ECOFIN being able to change or to oppose but being publicly accountable of their decisions in a special procedure of trans-European public debate among professionals organized by the European Parliament.

The purpose is to separate explicitly technical analysis from political decisions, preventing the damages from too dogmatic positions as this has been the case since the euro creation. Politics must remain in its own realm with political choices being transparently decided by elected power after previous technical assessments providing the cost/benefits of any action. This split makes authorities more accountable to public opinion. Both technicians and politicians will become more accountable of critical political decisions (like the use of EDA solidarity and its conditionality) as a result of professional debates, Parliaments' hearings (European and national) and trans-European debates.

Concretely, the existing EFB would be strengthened and included in the broader EMB as a specialized department in charge of fiscal policies, proposing to simplify 
the SGP. A full team of independent economists would cover the other economic policies relevant for EMU. Operationally, this would be easy to do by moving some experts from DG ECFIN of the Commission to the EMB plus acknowledged experts proposed by the European Parliament together with the Commission and approved by the ECOFIN. This EMB would issue and publish regular technical reports assessing the macroeconomic development and the policy-mix stances. In addition, EMB would be responsible for issuing the technical assessments and conditionality proposed to Commission/ECOFIN decisions for getting access to the solidarity facilities or for being rated as blue-bonds or red-bonds. Then, Commission would formally — but publicly - report to the ECOFIN, taking position on the EMB proposals. Any discrepancy with the EMB report would be intensively scrutinized by the EP, the financial press, the think-tanks, International Financial Institutions and the international economist community, creating some "cooperative competition" between Commission and EMB, stimulating a broad public debate across the EU before ECOFIN final decisions. In case of significant discrepancies between final decisions and EMB, a special hearing with additional experts would be organized by the European Parliament and published.

The purpose is to restore the spirit of the Treaty by increasing transparency and accountability and creating horizontal debates across the whole EU reducing the democratic gap and improving the existing decision making of ECOFIN and EP, ultimate legitimate actors.

\section{References}

Ghymers, C. (1995). La coordination des politiques économiques dans la Communauté européenne: Une évaluation en vue de la Conférence Intergouvernementale. Revue du Marché Commun n 385, February 1995.

Ghymers, C. (2015). Une relecture du Plan Werner par rapport à ses antécédents et à ses successeurs. In E. Danescu \& S. Muñoz (Eds.), Pierre Werner and Europe: His approach, action and legacy. Brussels, New York: OIE-Peter Lang.

Open Access This chapter is licensed under the terms of the Creative Commons Attribution 4.0 International License (http://creativecommons.org/licenses/by/4.0/), which permits use, sharing, adaptation, distribution and reproduction in any medium or format, as long as you give appropriate credit to the original author(s) and the source, provide a link to the Creative Commons license and indicate if changes were made.

The images or other third party material in this chapter are included in the chapter's Creative Commons license, unless indicated otherwise in a credit line to the material. If material is not included in the chapter's Creative Commons license and your intended use is not permitted by statutory regulation or exceeds the permitted use, you will need to obtain permission directly from the copyright holder.

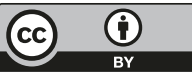

